\title{
Comparative effects of very low-carbohydrate, high-fat and high- carbohydrate, low-fat weight-loss diets on bowel habit and faecal short-chain fatty acids and bacterial populations
}

\author{
Grant D. Brinkworth, Manny Noakes, Peter M. Clifton and Anthony R. Bird* \\ Preventative Health National Research Flagship, Commonwealth Scientific and Industrial Research Organisation - Human \\ Nutrition, Adelaide, South Australia, Australia \\ (Received 25 March 2008 - Revised 28 August 2008 - Accepted 3 September 2008 - First published online 19 February 2009)
}

Very low-carbohydrate diets are often used to promote weight loss, but their effects on bowel health and function are largely unknown. We compared the effects of a very low-carbohydrate, high-fat (LC) diet with a high-carbohydrate, high-fibre, low-fat (HC) diet on indices of bowel health and function. In a parallel study design, ninety-one overweight and obese participants (age 50.6 (SD 7.5) years; BMI 33.7 (SD 4.2$) \mathrm{kg} / \mathrm{m}^{2}$ ) were randomly assigned to either an energy-restricted (about 6-7 MJ, 30\% deficit) planned isoenergetic LC or HC diet for 8 weeks. At baseline and week $8,24 \mathrm{~h}$ urine and faecal collections were obtained and a bowel function questionnaire was completed. Compared with the HC group, there were significant reductions in the LC group for faecal output (21 (SD 145) v. - 61 (SD 147) g), defecation frequency, faecal excretion and concentrations of butyrate $(-0.5(\mathrm{SD} 10.4) v .-3.9(\mathrm{SD} 9.7) \mathrm{mmol} / \mathrm{l})$ and total SCFA (1.4 (SD 40.5) v. -15.8 (SD 43.6) mmol/l) and counts of bifidobacteria $(P<0.05$ time $\times$ diet interaction, for all). Urinary phenols and $p$-cresol excretion decreased $(P \leq 0.003$ for time $)$ with no difference between diets $(P \geq 0 \cdot 25)$. Faecal form, $\mathrm{pH}$, ammonia concentration and numbers of coliforms and Escherichia coli did not change with either diet. No differences between the diets were evident for incidences of adverse gastrointestinal symptoms, which suggests that both diets were well tolerated. Under energy-restricted conditions, a short-term LC diet lowered stool weight and had detrimental effects on the concentration and excretion of faecal SCFA compared with an HC diet. This suggests that the long-term consumption of an LC diet may increase the risk of development of gastrointestinal disorders.

Bowel health: Dietary fibre: Ketogenic diets: Low-carbohydrate diets: Obesity

The global rise in obesity has stimulated considerable public interest in the use of very low-carbohydrate, high-fat (LC) diets, such as the 'Atkins diet', to promote weight loss ${ }^{(1)}$. Research to date has focused almost exclusively on weight reduction and CVD risk $^{(2)}$ with only limited consideration given to other clinically important endpoints such as the health of the gastrointestinal (GI) tract. Clearly, such information is imperative not only for optimising the overall efficacy of LC diets as a weight-management tool but also to ensure that health benefits resulting from improvement in weight status are realised.

Because LC diets severely restrict the intake of plant-based foods such as fruits, vegetables and grains, the predominant source of fibre in the human diet ${ }^{(3,4)}$, substantially reduced fibre intake following an LC diet is observed typically ${ }^{(5)}$. Plant foods such as whole grains contain a multitude of indigestible constituents that are beneficial for gut health. Although a common definition has yet to be reached ${ }^{(6)}$, the principal components of dietary fibre are carbohydrates that are resistant to digestion in the small intestine, notably NSP, resistant starches and non-digestible oligosaccharides ${ }^{(7)}$. Fibre is both preventative and therapeutic for a range of common large-bowel functional ailments including simple constipation and diverticular disease ${ }^{(8)}$. Generally, insoluble NSP increase stool bulk, shorten gut transit time and retain moisture in the faecal stream as a consequence of being only partially fermented by the colonic microbiota ${ }^{(8)}$. In comparison, soluble fibres are readily fermented but also facilitate laxation, albeit less effectively via mechanisms involving an increase in faecal biomass excretion. The bowel health benefits of carbohydrates reaching the colon are also mediated by the endproducts of their fermentation, including SCFA such as acetate, propionate and butyrate that are thought to be important for colonic function and mucosal health both directly and as a consequence of lowering the $\mathrm{pH}$ of the luminal environment ${ }^{(7)}$. In particular, butyrate, the principal energy source of colonocytes, has attracted considerable interest as a protective agent against colorectal cancer ${ }^{(9,10)}$ as a consequence of its ability to regulate gene expression and promote genetic stability by triggering apoptosis and differentiation of precancerous and transformed cells most likely via inhibition of histone deacetylase ${ }^{(11)}$.

Given that dietary fibre is important for preventing and/or alleviating constipation and various bowel diseases ${ }^{(8)}$, and

Abbreviations: cfu, colony-forming units; GI, gastrointestinal; HC, high-carbohydrate, high-fibre, low-fat; LC, very low-carbohydrate, high-fat.

* Corresponding author: Dr Tony Bird, fax +6188303 8899, email tony.bird@csiro.au 
that diets low in NSP are associated with an increased risk of colorectal cancer ${ }^{(9,11)}$, it is not surprising that concern has been raised as to the possible adverse effects of LC diets on digestive health ${ }^{(5,12)}$. Despite this, there has been little scientific research on this subject and the impact of these dietary regimens on the gut is largely unknown. In an uncontrolled study, $57 \%$ of paediatric patients with epilepsy consuming an LC diet reported GI disturbances, such as nausea/vomiting, diarrhoea or constipation ${ }^{(13)}$. Similarly, two other studies have reported greater incidences of constipation and/or diarrhoea following an energy-reduced LC diet compared with a conventional high-carbohydrate, low-fat (HC) $\operatorname{diet}^{(14,15)}$. However, these findings were based on incidental observations rather than systematic evaluation and consequently did not address indices of bowel health. Also, energy intake was not precisely controlled. In the only known study to date that has studied markers of bowel health, Duncan et al. ${ }^{(16)}$ showed in healthy, obese individuals that faecal concentrations of total and major individual SCFA and ammonia were significantly lower after consuming an LC diet (4\% of energy as carbohydrate) compared with the consumption of a diet containing moderate or high amounts of carbohydrate (35 and $52 \%$ of energy as carbohydrate, respectively). The proportion of faecal bacteria subgroup of clostridial cluster XIVa (Roseburia intestinalis and Eubacterium rectale) and bifidobacteria also declined as carbohydrate intake decreased. However, this study was limited in that it involved a relatively small number of subjects, a brief dietary intervention (28d) and the diets were consumed ad libitum in which energy intake differed between treatments. To date, no known study has evaluated the effects of an isoenergetic LC diet compared with an $\mathrm{HC}$ diet during weight loss on markers of bowel health and function in a controlled clinical trial.

\section{Methods \\ Participants and design}

The details of the design and other aspects of the study are described elsewhere ${ }^{(17)}$. In brief, 121 overweight or obese men and women (BMI $26-44 \mathrm{~kg} / \mathrm{m}^{2}$; age $24-64$ years) with abdominal obesity and the presence of at least one other metabolic risk factor delineated by the International Diabetes Foundation (a fasting glucose of $>6.11 \mathrm{mmol} / \mathrm{l}$; fasting TAG $>1.7 \mathrm{mmol} / \mathrm{l}$; fasting HDL-cholesterol $<1.03 \mathrm{mmol} / \mathrm{l}$ (men) or $<1.30 \mathrm{mmol} / \mathrm{l}$ (women); blood pressure $\geq 130 \mathrm{mmHg}$ (systolic) or $\geq 85 \mathrm{mmHg}$ (diastolic) $)^{(18)}$ were recruited by public advertisement to participate in an 8-week out-patient clinical trial. Before study commencement, participants completed a health-screening questionnaire and potential participants were excluded if they had a history of liver, cardiovascular, peripheral vascular, respiratory, GI, renal or hepatic disease or a malignancy. Exclusion criteria also included the regular use (one or more per week) of any form of drug therapy, medication or supplements such as laxatives or antibiotics that may interfere with bowel function or the validity of the study. The protocol and the potential risks and benefits of the study were fully explained to the participants before they provided written informed consent. All experimental procedures were approved by the Human Ethics Committee of the Commonwealth Scientific and Industrial Research Organisation (CSIRO). The trial was registered with the Australian Clinical Trials Registry (ACTR) ACTR No. 12606000203550.

\section{Study design}

In a parallel study design, participants were randomly assigned to consume either an LC or a conventional $\mathrm{HC}$ diet for 8 weeks. Both diets were energy-restricted and matched for energy. At baseline (week 0) and after the intervention (week 8) participants were required to collect during a $24 \mathrm{~h}$ period their total urine and stool output and complete a questionnaire assessing their bowel function and wellbeing. At each of the sampling periods, subjects collected all of their stools into a plastic bag placed over the toilet bowl. Separate bags were used for each bowel motion. Immediately after defecation, air was expelled from the plastic bag, which was then sealed, labelled and stored between two ice bricks in a polystyrene cooler $\left(4^{\circ} \mathrm{C}\right)$ for up to $24 \mathrm{~h}$ before being taken to the laboratory at the end of the collection periods. Faecal form was assessed using the Bristol stool scale ${ }^{(19)}$, as soon as the stool sample arrived at the laboratory. The samples were then stored at $-20^{\circ} \mathrm{C}$ until required for analysis. Defecation frequency was calculated according to the number of stool collection bags used per collection period. The $24 \mathrm{~h}$ urine sample was collected into an empty container and stored in an insulated cooler bag with ice bricks $\left(4^{\circ} \mathrm{C}\right)$ during the collection period. At the completion of the collection, the sample was then delivered to the laboratory and a spot urine sample was sampled and frozen $\left(-80^{\circ} \mathrm{C}\right)$ until analysis at the end of the study. Apart from the prescribed dietary intervention, participants were asked to maintain their usual lifestyle throughout the study.

\section{Dietary intervention and assessment}

The planned macronutrient profiles of the dietary interventions were as follows: LC diet, $35 \%$ of total energy as protein, $61 \%$ as fat and $4 \%$ as carbohydrate; $\mathrm{HC}$ diet, $24 \%$ as protein $30 \%$ as fat and $46 \%$ as carbohydrate. The diets were designed to be isoenergetic with a moderate energy restriction of approximately $30 \%$ energy (about $6000 \mathrm{~kJ}$ for women and about $7000 \mathrm{~kJ}$ for men) for 8 weeks. Key foods representative of each diet's macronutrient profile were supplied on a fortnightly basis for the 8 weeks to aid compliance. These foods were generally uncooked, but pre-weighed to provide approximately $30 \%$ of total energy. The dietary plan was structured to include specific daily quantities of foods to ensure the correct macronutrient and energy requirements (Table 1). These foods were listed in a food record that participants completed on a daily basis. Detailed dietary advice, meal planning and recipe information were provided at baseline and every 2 weeks by a qualified dietitian. We analysed three consecutive days (one weekend day and two weekdays) from the semiquantitative food record of each 2-week period, while the volunteer was present to ensure accuracy, using Foodworks Professional Edition, version 4 software (1998; Xyris Software, Highgate Hill, Qld, Australia), a computerised database of Australian foods. An average nutrient intake was then calculated from the fortnightly food records to represent the dietary intake during the study. At weeks 0 and 8, subjects also completed a validated seventy-four-item semi-quantitative, 
Table 1. Prescriptive food composition of the treatment diets

\begin{tabular}{|c|c|}
\hline LC $(6000 \mathrm{~kJ})$ & $\mathrm{HC}(6000 \mathrm{~kJ})$ \\
\hline $125 \mathrm{ml}$ full-fat milk & $40 \mathrm{~g}$ high-fibre bran cereal \\
\hline $70 \mathrm{~g}$ full-fat cheddar cheese & Two slices wholegrain bread $(35 \mathrm{~g})$ \\
\hline $\begin{array}{l}100 \mathrm{~g} \text { (cooked weight) ham, } \\
\text { tuna, beef, chicken, turkey }\end{array}$ & $300 \mathrm{ml}$ skimmed milk \\
\hline $\begin{array}{l}300 \mathrm{~g} \text { (raw protein food) } \\
\text { beef, chicken, fish }\end{array}$ & $20 \mathrm{~g}$ reduced-fat cheese (twice per week) \\
\hline One medium $(50-55 \mathrm{~g})$ egg & $300 \mathrm{~g}$ fruit \\
\hline $\begin{array}{l}\text { At least } 2.5 \text { cups green } \\
\text { vegetables }\end{array}$ & $\begin{array}{l}150 \mathrm{~g} \text { raw meat, beef, chicken, pork, } \\
\text { lamb (five times per week) }\end{array}$ \\
\hline $\begin{array}{l}25 \mathrm{~g} \text { (five teaspoons) oil or } \\
\text { butter }\end{array}$ & $150 \mathrm{~g}$ fish (once per week) \\
\hline $\begin{array}{l}40 \mathrm{~g} \text { raw, unsalted mixed } \\
\text { nuts }\end{array}$ & At least 2.5 cups vegetables \\
\hline \multirow[t]{9}{*}{$\begin{array}{l}\text { Two standard alcoholic } \\
\text { drinks per week (optional) }\end{array}$} & $\begin{array}{l}\text { One medium potato (three times per } \\
\text { week) }\end{array}$ \\
\hline & $\begin{array}{l}100 \mathrm{~g} \text { (dry weight) pasta or rice (four } \\
\text { times per week) }\end{array}$ \\
\hline & $100 \mathrm{~g}$ bean lentils (twice per week) \\
\hline & $\begin{array}{l}200 \mathrm{~g} \text { diet yoghurt (three times per } \\
\text { week) }\end{array}$ \\
\hline & $20 \mathrm{~g}$ raw unsalted nuts \\
\hline & $50 \mathrm{~g}$ tinned fish (three times per week) \\
\hline & 2 tsp polyunsaturated margarine \\
\hline & $\begin{array}{l}3 \text { tsp vegetable oil, for example, olive or } \\
\text { rapeseed oil }\end{array}$ \\
\hline & $\begin{array}{l}\text { Two standard alcoholic drinks per week } \\
\text { (optional) }\end{array}$ \\
\hline
\end{tabular}

LC, low-carbohydrate high-fat diet; HC, high-carbohydrate low-fat diet.

self-administered $\mathrm{FFQ}^{(20)}$ to provide information of dietary habits at baseline and for comparison at week 8 .

\section{Bowel function questionnaire}

A self-administered questionnaire was used to provide a subjective assessment of bowel function and wellbeing that asked subjects to provide an assessment of bowel function for: (1) the total number of bowel actions during the $24 \mathrm{~h}$ collection period; (2) the total number of bowel actions in the $7 \mathrm{~d}$ before the collection period; (3) frequency of flatulence; (4) ease of laxation during the $24 \mathrm{~h}$ collection period $(6=$ very soft/easy, $5=$ moderately soft/easy, $4=$ slightly soft/easy, $3=$ slightly hard/difficult, $2=$ moderately hard/difficult, $1=$ very hard/difficult); (5) presence of cramping; (6) presence of bloating.

\section{Faecal and urine analyses}

Biochemical and bacteriological analyses were performed in duplicate using standard published procedures. Urine samples were thawed at room temperature and total phenols and $p$-cresol were determined by an HPLC procedure based on the methods of Murray \& Adams ${ }^{(21)}$ and Yoshikawa et al. ${ }^{(22)}$. Briefly, an internal standard (4-ethyl-phenol, $0.3 \mathrm{mmol} / \mathrm{l}$; Sigma Aldrich, Castle Hill, NSW, Australia) was added to samples of urine which were then acidified with $2 \mathrm{M}-\mathrm{HCl}$, boiled for $30 \mathrm{~min}$, distilled under vacuum and phenol and $p$-cresol in the distillates quantified using a reverse-phase Chromopack HPLC Microsorb column $(250 \mathrm{~mm} \times 4.6 \mathrm{~mm}$; Varian, Melbourne, Vic, Australia). The mobile phase was acetonitrile-water $(30: 70, \mathrm{v} / \mathrm{v} ; \mathrm{pH} 3 \cdot 2)$, the flow rate was
$1 \mathrm{ml} / \mathrm{min}$, the injection volume was $20 \mu \mathrm{l}$ and the column oven temperature was set at $28^{\circ} \mathrm{C}$. Phenol and $p$-cresol were detected at the wavelength of $275 \mathrm{~nm}$ using a UV/Vis-detector (LC1200; GBC, Adelaide, SA, Australia).

Faecal collections from each volunteer were thawed at room temperature and mixed thoroughly, the total weight recorded, and then duplicate samples analysed as follows. Specimens (approximately $3 \mathrm{~g}$ ) were freeze-dried to constant weight and DM recorded. For SCFA, samples $(1 \mathrm{~g})$ were diluted 3-fold with internal standard (1.68 mM-heptanoic acid; Sigma Aldrich), centrifuged ( $3000 \mathrm{~g}$ for $15 \mathrm{~min}$ at $4^{\circ} \mathrm{C}$ ) and the $\mathrm{pH}$ of the supernatant fraction measured by inserting an appropriate glass probe. A sample $(150 \mu \mathrm{l})$ of supernatant fraction was acidified with $30 \mu \mathrm{l}$ of $0.16 \mathrm{M}$-orthophosphoric acid and vacuum distilled at low temperature ${ }^{(23)}$. Individual SCFA in the distillates were separated and quantified by capillary GC (5890 series II; Hewlett Packard, North Ryde, NSW, Australia) as described previously ${ }^{(24)}$. The GC was equipped with a flame ionisation detector, split-less injector and a Zebron ZB-FFAP $30 \mathrm{~m} \times 0.53 \mu \mathrm{m}$ capillary column with $0.1 \mu \mathrm{m}$ film thickness (Phenomenex, Pennant Hills, NSW, Australia). Injector and detector temperatures were both $210^{\circ} \mathrm{C}$, and the column temperature program was $120^{\circ} \mathrm{C}$ held for $0.5 \mathrm{~min}$ and then raised at $30^{\circ} \mathrm{C} / \mathrm{min}$ to reach a final column temperature of $190^{\circ} \mathrm{C}$. The carrier gas used was $\mathrm{He}$ (head pressure $50 \mathrm{kPa}$ ) and an injection volume of $0.2 \mu \mathrm{l}$ was used. Total SCFA concentration was calculated as the sum of acetic, propionic, butyric, isobutyric, caproic, isovaleric and valeric acid concentrations. Faecal SCFA excretion $(\mathrm{mmol} / \mathrm{d})$ was calculated as: SCFA concentration $(\mathrm{mmol} / \mathrm{l}) \times$ wet faecal weight $(\mathrm{g} / \mathrm{d}) \times$ faecal water content $(\mathrm{g} / 100 \mathrm{~g}) \times 10^{-5}$.

Faecal ammonia content was determined using the indophenol blue procedure ${ }^{(25)}$. Briefly, faecal specimens $(0.5 \mathrm{~g})$ were mixed with 9 volumes of distilled water and the slurry centrifuged at $2000 \mathrm{~g}$ for $10 \mathrm{~min}$. A sample $(100 \mu \mathrm{l})$ of supernatant fraction was diluted 1:10 with water, $2 \mathrm{ml}$ of an aqueous phenol $(0.1 \mathrm{~mol} / \mathrm{l})$ plus sodium nitroprusside $(0.17 \mathrm{mmol} / \mathrm{l}) \mathrm{sol}-$ ution added followed immediately by $2 \mathrm{ml}$ of alkaline sodium hypochlorite $(5.4 \mathrm{mmol} / \mathrm{l})$. The samples were vortexed before being heated for $10 \mathrm{~min}$ at $60^{\circ} \mathrm{C}$ in a shaking water-bath. They were then cooled quickly to room temperature. The optical density $(625 \mathrm{~nm})$ of the blue-coloured endproduct (indophenol) was measured by colorimetry and the ammonia concentration determined from a standard curve based on appropriate reference solutions. Bacteria were enumerated using conventional selective plating methods as described previously $^{(24)}$. Bifidus blood, Rogosa (Oxoid CM627), Columbia blood (Oxoid CM 331) and Chromogenic Escherichia colil Coliform (Oxoid CM956) medium were used for the selective enumeration of bifidobacteria, lactobacilli, total anaerobes, and E. coli, coliforms and total aerobes, respectively. Colonies characteristic of each bacterial group were visually counted and the concentration calculated as colony-forming units (cfu)/g wet weight.

\section{Statistical analysis}

Before hypothesis testing, data were examined for normality and for non-normally distributed variables (urinary phenols, faecal concentration and excretion of acetate, propionic, butyrate and total SCFA, faecal bacterial variables, faecal 
ammonia, and the self-reported number of bowel actions, flatulence episodes and ease of laxation) a logarithmic transformation was performed before analysis. Dietary data and differences in baseline characteristics between groups were compared using independent $t$ tests for continuous variables and the Pearson $\chi^{2}$ test for categorical variables $(P<0.05$; two-tailed tests). The effect of the dietary intervention was assessed using repeated-measures ANOVA with time as the within-subject factor and diet (LC v. HC) as the between-subject factor. Analysis of covariance was used to adjust for differences in weight loss. Where there was a significant main effect, post hoc comparisons were performed as appropriate with adjustment for multiple comparisons to determine differences between group means. Sex was shown to have no significant effect for any of the primary outcome measures and was therefore excluded from the model. Correlational analysis was used to determine relationships between variables. Partial correlation was performed to assess the independent contribution of dietary factors to the outcome measures. Statistical analyses were performed with SPSS 14.0 for Windows (SPSS Inc., Chicago, IL, USA). Statistical significance was set at $P<0 \cdot 05$. All data are presented as mean values and standard deviations, unless otherwise stated.

\section{Results \\ Participants}

Of the 121 participants who were enrolled, twelve participants withdrew before commencement of the study and an additional ten participants withdrew throughout the intervention. Of those who withdrew throughout the intervention, four did so due to an inability to comply with the dietary protocol (three from the LC group and one from the HC group), five were lost to follow-up and did not attend the follow-up clinic appointments for assessment or did not provide a faecal sample (two from the LC group and three from the HC group) and one individual in the LC group withdrew owing to illness unrelated to the study. Data from an additional six individuals (three from both the LC and HC groups) who were taking and/or commenced fibre or laxative supplements or were taking antibiotics were also excluded from analysis. Data for an additional two subjects in the $\mathrm{HC}$ group who reported food poisoning or experienced symptoms of a GI upset before test sample collection were also excluded from the analysis. The final analysis and the data reported are for the ninety-one remaining participants. Age (LC 50.4 (SD 7.7) years; HC 51.0 (SD 7.5) years), body weight (LC 94.4 (SD 14.5) kg; HC 96.7 (SD 13.7) kg), BMI (LC 33.5 (SD 4.1) $\mathrm{kg} / \mathrm{m}^{2}$; HC 33.9 (SD 4.4) $\mathrm{kg} / \mathrm{m}^{2}$ ) and sex distribution (LC, eighteen male and thirty female; $\mathrm{HC}$, eighteen male and twenty-five female) were similar in both groups $(P \geq 0.44)$.

\section{Dietary analysis and compliance}

The reported dietary intakes are consistent with the prescribed dietary treatments (Table 2). There was no difference in reported total energy intake between the two diet groups $(P=0.21)$. The intake of carbohydrate, sugars, starch and fibre was significantly higher and fat, protein and cholesterol intakes were significantly lower in the HC group compared
Table 2. Dietary intake of the study groups assessed using daily weighted food checklists $\dagger$

(Mean values and standard deviations)

\begin{tabular}{|c|c|c|c|c|}
\hline \multirow[b]{2}{*}{ Nutrient } & \multicolumn{2}{|c|}{ LC } & \multicolumn{2}{|c|}{$\mathrm{HC}$} \\
\hline & Mean & SD & Mean & SD \\
\hline \multicolumn{4}{|l|}{ Total carbohydrate } & 734.7 \\
\hline $\mathrm{g}$ & $19 \cdot 7$ & 3.8 & $170 \cdot 6^{\star}$ & $26 \cdot 4$ \\
\hline$\%$ Energy & $5 \cdot 0$ & 0.9 & $46 \cdot 3^{*}$ & $3 \cdot 7$ \\
\hline Fibre $(\mathrm{g})$ & 13.0 & $2 \cdot 0$ & $31.5^{\star}$ & 5.0 \\
\hline Sugars $(\mathrm{g})$ & $15 \cdot 7$ & $2 \cdot 6$ & $61 \cdot 3^{\star}$ & $9 \cdot 3$ \\
\hline Starch $(g)$ & $3 \cdot 2$ & $2 \cdot 4$ & $107 \cdot 0^{*}$ & $2 \cdot 4$ \\
\hline \multicolumn{5}{|l|}{ Protein } \\
\hline $\mathrm{g}$ & 134.4 & $9 \cdot 2$ & $87 \cdot 2^{*}$ & 9.0 \\
\hline$\%$ Energy & $35 \cdot 1$ & $2 \cdot 0$ & $24 \cdot 0^{*}$ & 1.6 \\
\hline \multicolumn{5}{|l|}{ Fat } \\
\hline g & $103 \cdot 2$ & 13.5 & $47 \cdot 0^{*}$ & $7 \cdot 8$ \\
\hline \% Energy & 58.4 & $2 \cdot 6$ & $28 \cdot 1^{*}$ & 3.6 \\
\hline Saturated fat (\% energy) & $21 \cdot 0$ & $2 \cdot 1$ & $5 \cdot 6^{\star}$ & 0.8 \\
\hline $\begin{array}{l}\text { Monounsaturated fat } \\
\text { (\% energy) }\end{array}$ & $25 \cdot 1$ & $2 \cdot 1$ & $12 \cdot 5^{\star}$ & $2 \cdot 2$ \\
\hline $\begin{array}{l}\text { Polyunsaturated fat } \\
\text { (\% energy) }\end{array}$ & 7.9 & $1 \cdot 1$ & $6 \cdot 9^{*}$ & 1.0 \\
\hline Cholesterol (mg) & $602 \cdot 3$ & $89 \cdot 6$ & $140 \cdot 7^{\star}$ & 29.6 \\
\hline Alcohol (g) & 3.4 & 4.6 & 3.4 & 4.0 \\
\hline
\end{tabular}

LC, low-carbohydrate high-fat diet; $\mathrm{HC}$, high-carbohydrate low-fat diet.

* Mean value was significantly different from that for the LC group $(P<0.001$; independent-samples $t$ test).

†Participants completed daily semi-quantitative food records. Three days (two weekdays and one weekend day) of dietary data were analysed at weeks 2, 4, 6 and 8 .

with the LC group. Based on data obtained from the FFQ, compared with baseline, mean fibre intake decreased from $22 \mathrm{~g} / \mathrm{d}$ to $13 \mathrm{~g} / \mathrm{d}(9.3$ (SD $11 \cdot 1) \mathrm{g} / \mathrm{d})$ in the LC group, but increased from $24 \mathrm{~g} / \mathrm{d}$ to $28 \mathrm{~g} / \mathrm{d}(3.8$ (SD 7.4) $\mathrm{g} / \mathrm{d}$ ) in the HC group with energy restriction $(P<0.001$ time $\times$ diet interaction). The effects of the diets on body weight were as expected and have been reported and discussed elsewhere ${ }^{(17)}$. Briefly, after the intervention, there was a significant time $\times$ diet interaction for weight loss $(P=0.006)$; the LC diet group had a significantly greater weight loss than the HC diet group (7.6 (SD 2.6) and 6.0 (SD 2.8) kg, respectively).

\section{Faecal weight, water content, $p H$ and defecation frequency}

The faecal characteristics are presented in Table 3. There was a reduction in daily faecal output in the LC group compared with the HC group (LC - 61 (SD 147) g; HC 21 (SD 145) g; $P=0.01$ time $\times$ diet interaction). At week 8 , faecal output was positively, but weakly correlated with level of intake of fibre $(r 0.36 ; P=0.001)$ and carbohydrate $(r 0.33 ; P=0.002)$ and negatively correlated with fat intake $(r-0.27 ; P=0.01)$, but was not related to protein intake. The association between fat intake and faecal output was no longer evident after controlling for carbohydrate and fibre intake with partial correlation.

Faecal moisture decreased in both diet groups $(P<0 \cdot 001)$, but there was no differential effect of diet $(P=0 \cdot 19)$. There was a trend for a reduction in faecal $\mathrm{pH}(P=0.09)$, with no effect of diet composition $(P=0 \cdot 69)$. Neither faecal ammonia concentrations nor faecal form changed either with time or diet $(P>0.32)$. Faecal form was comparable for the two 
Table 3. Effect of diet on faecal weight, water content, $\mathrm{pH}$ and defecation frequency (Mean values and standard deviations)

\begin{tabular}{|c|c|c|c|c|c|c|c|c|}
\hline & \multicolumn{4}{|c|}{ LC } & \multicolumn{4}{|c|}{$\mathrm{HC}$} \\
\hline & \multicolumn{2}{|c|}{ Week 0} & \multicolumn{2}{|c|}{ Week 8} & \multicolumn{2}{|c|}{ Week 0} & \multicolumn{2}{|c|}{ Week 8} \\
\hline & Mean & SD & Mean & SD & Mean & SD & Mean & SD \\
\hline Faecal weight $(\mathrm{g} / 24 \mathrm{~h})^{*}$ & 223.1 & $137 \cdot 3$ & $162 \cdot 3 \dagger$ & $140 \cdot 9$ & $225 \cdot 2$ & $130 \cdot 2$ & $245 \cdot 8$ & 135.5 \\
\hline Faecal moisture $(\mathrm{g} / 100 \mathrm{~g})$ & $74.0 \ddagger$ & $6 \cdot 6$ & $70 \cdot 7+\dagger$ & $8 \cdot 7$ & $76 \cdot 7$ & 5.5 & $75 \cdot 1+\dagger$ & $5 \cdot 1$ \\
\hline Faecal pH & $7 \cdot 13$ & 0.58 & $7 \cdot 04$ & 0.54 & $7 \cdot 12$ & 0.83 & 6.97 & 0.54 \\
\hline Faecal ammonia $(\mu \mathrm{mol} / \mathrm{g})$ & $26 \cdot 5$ & $9 \cdot 2$ & $32 \cdot 9$ & $19 \cdot 0$ & 37.5 & $21 \cdot 2$ & $32 \cdot 9$ & $14 \cdot 2$ \\
\hline Faecal form & 4.10‡ & 1.47 & 4.09 & 1.57 & 4.79 & 0.98 & 4.68 & 1.17 \\
\hline Defecation frequency (motions per $24 \mathrm{~h}$ ) & 1.65 & 0.73 & 1.23 & 0.59 & 1.56 & 0.70 & 1.42 & 0.70 \\
\hline
\end{tabular}

LC, low-carbohydrate high-fat diet; HC, high-carbohydrate low-fat diet.

* Significant time $\times$ diet interaction for response between diet groups based on the general linear model in repeated-measures ANOVA, with Bonferroni's adjustment for multiple comparison $(P=0.01)$.

Mean value was significantly different from that at baseline within the same group (time effect within each group): $† P=0.004, \dagger \dagger P<0.001$.

$\ddagger$ Mean value was significantly different from that for the $\mathrm{HC}$ group at baseline $(P<0.05$; independent-samples $t$ test .

diets ( $P=0 \cdot 22$, adjusted for baseline differences). There was a trend for a greater reduction in defecation frequency in the LC group compared with the HC group (LC -0.42 (SD 0.71) motions per $24 \mathrm{~h}$; HC -0.14 (SD 0.77 ) motions per $24 \mathrm{~h}$; $P=0.08$ time $\times$ diet interaction). Adjustment for weight loss in all of these analyses had no effect.

\section{Faecal concentration and excretion of total and individual} SCFA

There was a significant time $\times$ diet effect for faecal acetate $(P=0 \cdot 001)$, butyrate $(P=0 \cdot 04)$ and total SCFA concentration $(P=0.01)$, with concentrations decreasing by week 8 in the LC group ( -10.7 (SD 26.6), -3.9 (SD 9.7) and -15.8 (SD 43.6) $\mathrm{mmol} / \mathrm{l}$, respectively; $P \leq 0.04$ for all), but did not change significantly from week 0 in the $\mathrm{HC}$ group $(3 \cdot 3$ (SD $22 \cdot 3),-0.5(\mathrm{SD} \mathrm{10.4)}$ and $1.4(\mathrm{SD} 40.5) \mathrm{mmol} / \mathrm{l}$, respectively; $P \geq 0.83$ for all) (Table 4). Overall, there was no significant effect of diet for faecal propionic concentrations (LC -1.9 $(\mathrm{SD} 7.8) v . \mathrm{HC}-0.8(\mathrm{SD} 9.0) ; P=0.24)$. There were also no significant effects of weight loss on the diet effects observed for these variables. At week 8, faecal total SCFA concentration was positively correlated with the intake of fibre $(r 0.21 ; P=0.048)$ and carbohydrate $(r 0.22 ; P=0 \cdot 04)$.

Similar to the effects observed for faecal concentrations of total and individual SCFA, there was a significant time $\times$ effect of diet on the faecal excretion of acetate, propionic, butyrate and total SCFA $(P \leq 0.003)$, such that these variables decreased in the LC group (-2.7 (SD 10.2), -0.9 (SD 3.1), $-0.8(\mathrm{SD} 5.2)$ and $-4.6(\mathrm{SD} 18.7) \mathrm{mmol} / \mathrm{l}$, respectively; $P<0.001$ for all), but did not change in the HC group $(3.4$ (SD 15.9), $0 \cdot 0(\mathrm{SD} \mathrm{3.3)}, 0 \cdot 2(\mathrm{SD} \mathrm{3.5)}$ and $3.7(\mathrm{SD} 21.5) \mathrm{mmol} /$ 1 , respectively; $P \geq 0.31$ for all) (Table 4 ). No significant effect of weight loss differences was observed.

\section{Urinary phenols and p-cresols}

Urinary phenols were similar in both groups at week 0 (LC 14.9 (SD 11.2) $\mathrm{mg} / \mathrm{d}$; HC 15.0 (SD 17.3$) \mathrm{mg} / \mathrm{d} ; P=0.70)$. Urinary phenols decreased significantly in both treatment groups

Table 4. Effect of diet on faecal concentrations and excretion of total and individual SCFA (Mean values and standard deviations)

\begin{tabular}{|c|c|c|c|c|c|c|c|c|}
\hline & \multicolumn{4}{|c|}{ LC } & \multicolumn{4}{|c|}{$\mathrm{HC}$} \\
\hline & \multicolumn{2}{|c|}{ Week 0} & \multicolumn{2}{|c|}{ Week 8} & \multicolumn{2}{|c|}{ Week 0} & \multicolumn{2}{|c|}{ Week 8} \\
\hline & Mean & SD & Mean & SD & Mean & SD & Mean & SD \\
\hline \multicolumn{9}{|l|}{ Faecal concentration } \\
\hline Acetate $(\mathrm{mmol} / \mathrm{l})^{*}$ & $58 \cdot 5$ & $19 \cdot 1$ & $47.9 \dagger$ & $26 \cdot 6$ & $62 \cdot 4$ & $18 \cdot 5$ & $65 \cdot 7$ & $21 \cdot 7$ \\
\hline Propionate (mmol/l) & $17 \cdot 6 \ddagger$ & $7 \cdot 6$ & $15 \cdot 7$ & $8 \cdot 3$ & $21 \cdot 4$ & $7 \cdot 6$ & $20 \cdot 6$ & 8.5 \\
\hline Butyrate $(\mathrm{mmol} / \mathrm{l})^{*}$ & $18 \cdot 3$ & $9 \cdot 7$ & $14.4 \dagger$ & $10 \cdot 7$ & $21 \cdot 1$ & 8.9 & $20 \cdot 6$ & $10 \cdot 1$ \\
\hline Total SCFA (mmol/l)* & $102 \cdot 2$ & 33.5 & $86.4 \dagger$ & $45 \cdot 8$ & $113 \cdot 1$ & $31 \cdot 8$ & 114.5 & $38 \cdot 0$ \\
\hline \multicolumn{9}{|l|}{ Faecal excretion } \\
\hline Acetate $(\mathrm{mmol} / \mathrm{d})^{*}$ & $10 \cdot 1$ & $8 \cdot 2$ & $7.5 \dagger$ & $10 \cdot 8$ & $11 \cdot 7$ & $9 \cdot 1$ & $15 \cdot 0$ & $15 \cdot 1$ \\
\hline Propionate $(\mathrm{mmol} / \mathrm{d})^{\star}$ & $3 \cdot 3$ & 2.8 & $2.4 \dagger$ & $3 \cdot 3$ & $4 \cdot 2$ & $3 \cdot 8$ & $4 \cdot 2$ & 3.5 \\
\hline Butyrate $(\mathrm{mmol} / \mathrm{d})^{*}$ & 3.4 & $3 \cdot 1$ & $2.6 \dagger$ & $5 \cdot 0$ & 3.9 & 2.9 & $4 \cdot 1$ & $3 \cdot 0$ \\
\hline Total SCFA $(\mathrm{mmol} / \mathrm{d})^{*}$ & $18 \cdot 0$ & $14 \cdot 5$ & $13.4 \dagger$ & $19 \cdot 5$ & $21 \cdot 0$ & $15 \cdot 4$ & $24 \cdot 6$ & $20 \cdot 4$ \\
\hline
\end{tabular}

LC, low-carbohydrate high-fat diet; HC, high-carbohydrate low-fat diet

* Significant time $\times$ diet interaction for response between diet groups based on the general linear model in repeated-measures ANOVA, with Bonferroni's adjustment for multiple comparison $(P \leq 0.04)$.

† Mean value was significantly different from that at baseline within the same group (time effect) $(P \leq 0.04)$.

$\ddagger$ Mean value was significantly different from that for the $\mathrm{HC}$ group at baseline $(P<0.05$; independent-samples $t$ test). 
with energy restriction during the intervention ( $\mathrm{LC}-7.4$ (SD 7.8) $\mathrm{mg} / \mathrm{d} ; \mathrm{HC}-8.5$ (SD 14.6) $\mathrm{mg} / \mathrm{d} ; P<0.001$ for time), but there was no effect of diet $(P=0 \cdot 60)$. Urinary $p$-cresol levels were significantly higher on the LC diet compared with the $\mathrm{HC}$ diet at baseline (LC 94.9 (SD 43.2) $\mathrm{mg} / \mathrm{d}$; HC 56.6 (SD 28.0) $\mathrm{mg} / \mathrm{d} ; \quad P=0.001)$. Urinary $p$-cresol levels decreased in both diet groups during the study (LC -26.0 (SD 45.6) $\mathrm{mg} / \mathrm{d}$; HC - 11.9 (SD 34.6) $\mathrm{mg} / \mathrm{d} ; P=0.003$ for time), with no effect of diet $(P=0 \cdot 25)$.

\section{Enumeration of faecal bacteria}

There was a significant time $\times$ diet effect for total faecal anaerobes $(P=0.005)$, such that levels remained unchanged in the LC group ( -0.22 (SD 0.56) $\log _{10} \mathrm{cfu} / \mathrm{g}$ wet weight; $P=0.23$ ) but increased in the HC group (0.34 (SD 0.50) $\log _{10} \mathrm{cfu} / \mathrm{g}$ wet weight; $P=0.03$ ) (Fig. 1). The anaerobe:aerobe ratio remained unchanged throughout the study in both diet groups (data not shown). There was a significant time $\times$ diet effect for faecal bifidobacteria $(P<0.001)$ whereby levels decreased in the LC group ( -1.7 (SD 1.2) $\log _{10} \mathrm{cfu} / \mathrm{g}$ wet weight; $\left.P<0.001\right)$ and remained unchanged in the HC group (0.3 (SD 0.70) $\log _{10} \mathrm{cfu} / \mathrm{g}$ wet weight; $P=0 \cdot 22$ ) (Fig. 1). Faecal lactobacilli did not change significantly during the study $(P=0.07$; time effect), with no effect of diet evident $(P=0 \cdot 17)$. At baseline, there was no difference between the groups for the concentrations of either faecal coliforms (LC 6.3 (SD 2.0) $\log _{10} \mathrm{cfu} / \mathrm{g}$ wet weight; HC 6.7 (SD 1.4) $\log _{10} \mathrm{cfu} / \mathrm{g}$ wet weight; $\left.P=0.60\right)$ or $E$. coli (LC 6.0 (SD 2.1) $\log _{10} \mathrm{cfu} / \mathrm{g}$ wet weight; HC 6.4 (SD 1.7) $\log _{10} \mathrm{cfu} / \mathrm{g}$ wet weight; $P=0 \cdot 60$ ). Neither parameter changed significantly in either diet group during the intervention $(P \geq 0 \cdot 20)$.

\section{Bowel habit}

The number of self-reported bowel actions during the $24 \mathrm{~h}$ sample collection period decreased during the study (LC 1.7 (SD 0.8 ) actions per $24 \mathrm{~h}$ to 1.3 (SD 0.8 ) actions per $24 \mathrm{~h}$; HC 1.7 (SD 0.7) actions per $24 \mathrm{~h}$ to 1.5 (SD 0.7) actions per $24 \mathrm{~h} ; P=0.003$ for time), with no effect of diet $(P=0.35$; time $\times$ diet effect). The number of bowel actions reported during the $7 \mathrm{~d}$ before sample collection was reduced more in the LC group (10.4 (SD 6.5) actions per $7 \mathrm{~d}$ to 7.2 (SD 4.5) actions per $7 \mathrm{~d}$ ) compared with the HC group (10.8 (SD 4.5) actions per $7 \mathrm{~d}$ to 9.0 (SD 4.4) actions per $7 \mathrm{~d})(P=0.04$; time $\times$ diet interaction). Furthermore, by week 8 , a significantly greater proportion of subjects in the LC group compared with in the HC group had reported a reduction in the number of bowel actions during the $7 \mathrm{~d}$ before the collection period (LC $75 \%$; HC $54 \% ; P=0.048$ ). There was a significant time $\times$ diet effect for the number of reported flatulence episodes $(P=0 \cdot 01)$, such that there was a significant reduction in the LC group (6.7 (SD 5.4) episodes per $24 \mathrm{~h}$ to 3.9 (SD 2.8) episodes per $24 \mathrm{~h} ; P<0.001$ ), but no change in the HC group (7.0 (SD 5.8) episodes per $24 \mathrm{~h}$ to 7.2 (SD 5.9) episodes per $24 \mathrm{~h} ; P=0 \cdot 82$ ). The proportion of subjects reporting a reduction in the number of flatulence episodes at week 8 was greater in the LC group compared with in the HC group (LC $76 \% ; \mathrm{HC} 43 \% ; P=0.005)$. There was no significant effect of diet on ease of laxation (LC 4.3 (SD 3.5) to 3.8 (SD 1.4); HC 3.5 (SD 1.7) to 3.8 (SD 1.4); $P=0.06$; time $\times$ diet
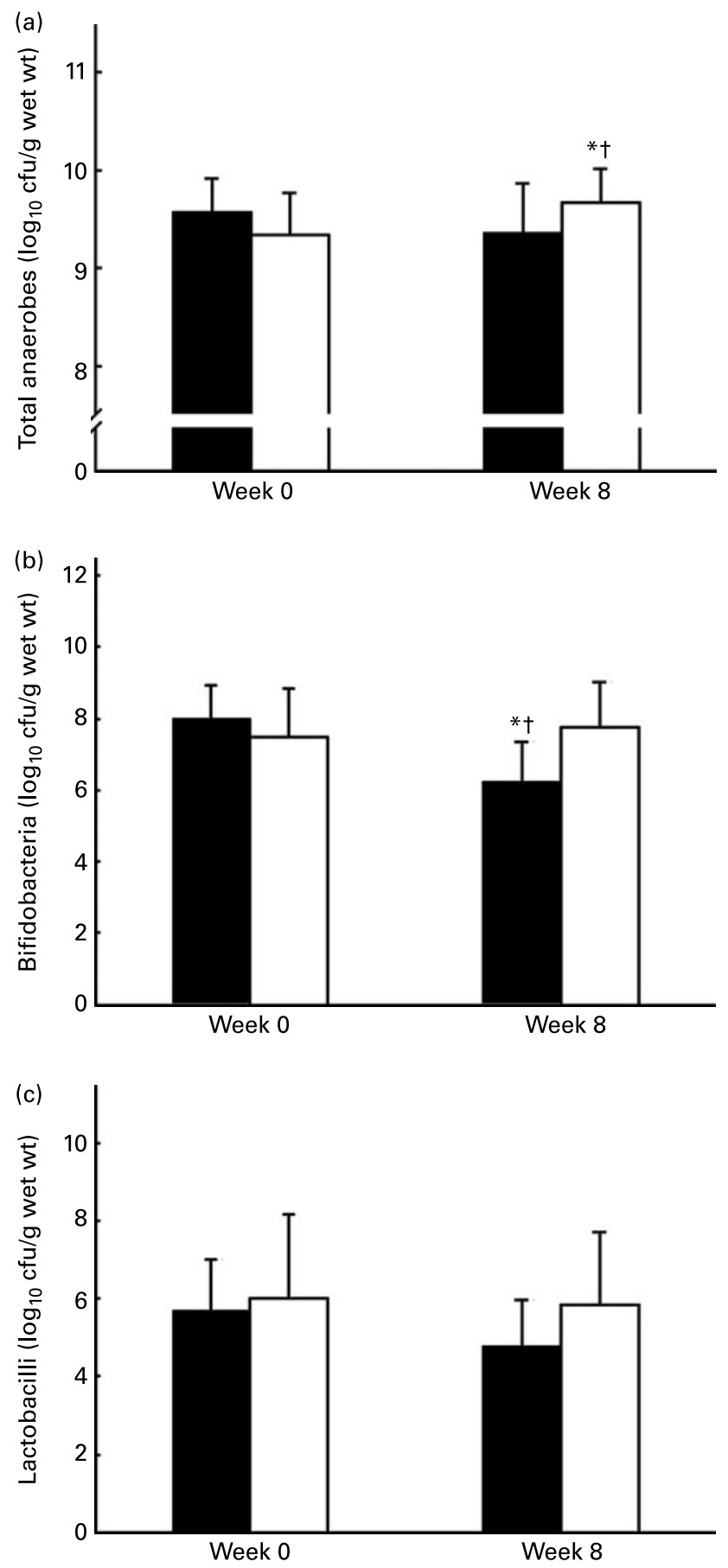

Fig. 1. Effect of diet on total anaerobes (a), bifidobacteria (b) and lactobacilli (c) in subjects given a low-carbohydrate, high-fat diet (ם) or a high-carbohydrate, low-fat diet $(\square)$. Values are means, with standard deviations represented by vertical bars. cfu, Colony-forming units. * Significant time $\times$ diet interaction, based on the general linear model in repeated-measures ANOVA, with post hoc adjustment for multiple comparisons $(P \leq 0.005)$. † Mean value was significantly different from that at week 0 within the same group (time effect) $(P \leq 0.03)$.

effect) and the proportion of subjects reporting reductions in the ease of laxation during the study was not different between groups (LC $46 \%$ v. HC $33 \% ; P=0 \cdot 19$ ). No substantial presence of bloating (LC, four subjects; HC, five subjects) or cramping (LC, five subjects; HC, two subjects) symptoms 
was evident with either diet. One subject in the LC group also reported having diarrhoea during the study.

\section{Discussion}

Both diet groups achieved a high level of dietary compliance as shown by the fact that weight loss was achieved and food intakes based on the dietary data were consistent with the diets prescribed. In support of this, plasma ketone bodies, previously reported elsewhere ${ }^{(17)}$, remained low in the HC group but were elevated in subjects consuming the LC diet, reflecting the lower carbohydrate intake. Dietary fibre consists of mainly non-digestible carbohydrates and, not unexpectedly, fibre intake was much lower in the LC group compared with the HC group (13 v. $32 \mathrm{~g} / \mathrm{d}$ ). For the LC diet, this was substantially less than the $21-38 \mathrm{~g} / \mathrm{d}$ recommended for adults by health authorities to maintain digestive health and function $^{(3,26)}$. For this reason, compromised bowel habit and poor bowel health are often cited concerns of LC diets ${ }^{(12)}$. However, to date, there has been a paucity of well-controlled studies evaluating these possible effects.

In the present study, both diets were well tolerated with no substantial presence of adverse GI symptoms such as abdominal pain, bloating, constipation and excessive flatulence. In contrast, Yancy et al. ${ }^{(15)}$ reported a greater frequency of constipation in overweight individuals consuming an LC diet compared with an $\mathrm{HC}$ diet $(68 v .35 \%)$. However, the present study reported greater drop-out amongst participants in the $\mathrm{HC}$ group that may explain at least in part the higher rate of constipation in the LC group, of which participants had greater opportunity to report adverse effects. The study by Yancy et al. ${ }^{(15)}$ was also substantially longer (24 weeks), suggesting that the present investigation may not have been long enough for any possible observable differences in symptoms of abdominal discomfort between the groups to have become evident. In the present study, subjects on the LC diet self-reported less frequent bowel movements (supported objectively by the tendency for a lower defecation frequency) that could in the long term result in GI discomfort and defecation difficulty. Further long-term controlled studies are required to establish these effects.

Daily wet stool weight declined substantially in the LC group whereas there was a small non-significant increase in the HC group, which most probably reflected changes in dietary fibre intake. In support of this, the change in faecal output was associated with fibre intake. Generally, the content of fat and meat in the diet is not believed to influence bowel habit greatly $^{(27,28)}$, although in some individuals high protein intake may slow colonic transit ${ }^{(27)}$. However, we showed that dietary protein level did not relate to faecal weight. Although there was a weak but significant correlation with fat intake, it was no longer evident after adjustment using partial analyses, suggesting that fat was not an important dietary factor in this regard and the initial correlation observed was a consequence of the replacement of carbohydrate in the LC diet. Increased stool bulk is associated with intestinal motility as evidenced by more frequent bowel movements and shortened colonic transit time ${ }^{(29,30)}$. Greater stool mass is postulated to reduce exposure of the colonic epithelium to potentially harmful agents in the faecal stream, including mutagens, carcinogens and procarcinogens ${ }^{(7)}$. For adults, presumably of normal weight, faecal output of at least $150-200 \mathrm{~g} / \mathrm{d}$ is considered necessary for maintaining normal bowel function and health and protection against large-bowel cancer ${ }^{(31,32)}$. In the present study, irrespective of the group differences, pre- and post-intervention stool weight reached this target. As our subjects were overweight or obese, the high faecal weights recorded at baseline (mean, $223 \mathrm{~g} / \mathrm{d}$ ) most probably reflected a high food intake and, presumably, comparatively large amounts of digesta reaching the colon from the small intestine. For similar reasons, this could possibly explain why individuals on the LC diet had relatively normal stool weights $(162 \mathrm{~g} / \mathrm{d})$ at week 8 , despite low fibre intake. Although subjects had hypoenergetic intakes and achieved a reduced body weight, on average they were still either overweight or obese at week 8 (BMI about $31 \mathrm{~kg} / \mathrm{m}^{2}$ ). The degree of energy restriction was what would be considered moderate and, consequently, absolute energy intakes were similar to those of normal-weight adults.

In the LC subjects, faecal frequency declined to a greater extent compared with the $\mathrm{HC}$ subjects, although there was no difference between the groups at week 8. Faecal form, which has been shown to correlate with intestinal transit rate $^{(19)}$ was not different between the groups. Fibre also increases defecation frequency ${ }^{(33)}$, but as with faecal moisture, there is an upper limit beyond which no additional effects of fibre are usually observed. However, despite the marked dietary differences, no differences between the diet groups or substantial presence of GI symptoms or defecation difficulty were reported by the volunteers.

The amount and composition of the ileal digesta has a major effect on large-bowel function primarily through its interaction with bacteria resident in that gut region. Fibre (especially the more fermentable forms, such as resistant starch) is quantitatively the most important dietary substrate for the colonic microflora and in accord with the observed correlation of fibre and carbohydrate intake, fermentation diminished on the LC diet as reflected by the lower faecal concentrations and excretion of total and the major individual SCFA, including butyrate. This is in direct agreement with the findings of Duncan et al. ${ }^{(16)}$ who showed a significant reduction in faecal SCFA and butyrate concentration in response to an LC compared with an $\mathrm{HC}$ diet in obese subjects that correlated with the level of carbohydrate intake. Although the diets in the present study had differential effects on SCFA concentrations, the relative molar proportions of the major individual SCFA were remarkably similar (data not shown).

Digesta transit rate has been shown to be a determinant of faecal SCFA concentration ${ }^{(33)}$. In the present study, defecation frequency was not different between the diets at week 8 and faecal consistency, which is an indicator of gut transit rate $^{(19)}$, remained stable in both groups. This suggests that gut transit was not affected by the experimental diets and that other reasons are probably responsible for the effects of the LC diet on faecal SCFA levels.

It is widely acknowledged that SCFA in general and butyrate in particular are important for maintaining normal bowel function and the integrity of the colonic mucosa ${ }^{(7,34)}$. Faecal butyrate concentration and excretion were 30-60\% lower on the LC diet, which suggests that adherence to this dietary regimen for an extended period may have adverse consequences for gut health $^{(9,10)}$. But despite the differences in SCFA concentrations 
between the groups, faecal $\mathrm{pH}$ was similar. Increased fermentation is the major process driving luminal acidification as a direct consequence of SCFA production, which is the major source of organic anions in the colon, and the utilisation of $\mathrm{NH}_{4}^{+}$to support bacterial proliferation ${ }^{(7)}$.

Although the observed potentially adverse effects of the LC diet on the various indices of bowel health are a probable consequence of the lower fibre intake, the actions of other dietary components associated with the LC diet, such as the high intake of protein and fat, should not be dismissed. It is believed that fermentation of undigested protein by the large-bowel microflora generates metabolites, such as ammonia, hydrogen sulfide and phenols, which are potential cytotoxins and carcinogens ${ }^{(8,35,36)}$. However, in spite of the relatively high protein intake with the LC diet, urinary excretion of phenols and $p$-cresols was reduced in association with energy restriction and associated weight loss in both diet groups with no difference in the response between them. Additionally, we did not observe any significant dietary differences in faecal concentrations of ammonia (Table 3), or branched-chain SCFA (data not shown) which are also products of bacterial protein breakdown ${ }^{(9,37)}$. Previous research has shown that the amount of protein reaching the colon from the small intestine increases with increasing protein intakes $^{(38)}$, as do levels of protein fermentation products generated by the colonic microflora ${ }^{(39,40)}$ and this may have adverse effects on bowel health ${ }^{(41-43)}$. However, in the present study we found no evidence that higher protein intake was associated with increased levels of potentially deleterious protein fermentation products. This raises the possibility that energy restriction may have enhanced the functional efficiency of the small intestine, increasing the absorption of available protein, thus reducing the amount of protein reaching the colon. Further research is required to evaluate intestinal assimilation of dietary protein in the context of an LC, energy-reduced diet. Whether luminal production of protein fermentation products is similar for the same dietary pattern during weight maintenance with a higher energy intake remains unknown.

The reduction in faecal bifidobacteria numbers concurs with a small previous study that also showed that faecal abundance of bifidobacteria in obese subjects was less on a high-protein/low-carbohydrate diet than on a medium-carbohydrate/high-protein diet ${ }^{(16)}$. High numbers of bifidobacteria and lactobacilli are considered important for the health of the colon ${ }^{(24,44,45)}$. Aside from the aforementioned changes no other effects of diet on the faecal microflora were discerned. The higher protein intake with the LC diet was not reflected in greater numbers of total coliforms or E. coli, which were quite uniform throughout the study.

The present study has some obvious limitations. The faecal collection period was relatively brief $(24 \mathrm{~h})$ and freezing of the stool samples was delayed until the end of the collection period. This may have increased the variability of certain endpoints (for example, stool weight) and reduced absolute numbers of some faecal bacterial groups (for example, total anaerobes and bifidobacteria ${ }^{(46)}$. However, that the faecal collection protocol was identical for all subjects suggests that observed treatment differences are in effect real. Furthermore, the large subject numbers also would have offset potential data variability brought about by the relatively short faecal collection period. The fact that treatment effects were observed for a majority of outcomes suggests that the study was sufficiently powered. The large-bowel microbiota also comprises extremely large numbers of diverse types of bacteria, the activities of which may have negative or positive effects on the host. Indeed, the gut microflora are implicated in the development and progression of serious large-bowel diseases, such as colorectal cancer ${ }^{(47,48)}$. But although the range of bacterial groups measured in the present study was somewhat limited, the endpoints examined were chosen because of their reported links to health outcomes. For instance, total anaerobes and aerobes were enumerated because the ratio of the size of these two populations (anaerobes:aerobes) has been linked to the risk of colon cancer ${ }^{(49)}$. Although not numerous in the human colon, coliform bacteria were enumerated because this group comprises a number of pathogens whereas alternatively bifidobacteria and lactobacilli are considered beneficial for human health. Certain non-digestible dietary carbohydrates, such as fructo-oligosaccharides, function as prebiotics in that they selectively stimulate the growth of these micro-organisms in the colon ${ }^{(45)}$. Counts of total bacteria were also required so as to ascertain possible selective changes in specific bacterial groups (such as bifidobacteria). However, the culture-based enumeration methods are limited technically and may not have been sufficiently sensitive to detect modest changes in bacterial numbers ${ }^{(50)}$. The use of specific and sensitive molecular microbiological techniques may have yielded more information on possible dietrelated changes in the composition of faecal microflora.

In conclusion, the short-term consumption of a moderate, energy-reduced LC diet was well tolerated and while it had no obvious impact on bowel habit, laxation or GI comfort, there were potentially adverse effects on a number of putative biomarkers of bowel health and function compared with an isoenergetic conventional $\mathrm{HC}$ diet in healthy overweight and obese subjects. These included lower total stool mass, less frequent bowel movements, reduced large-bowel fermentation as evidenced by a reduction in the concentration and excretion of faecal SCFA including butyrate, and an unfavourable shift in faecal microflora composition as shown by a marked reduction in the numbers of bifidobacteria, suggestive of poorer bowel health and an increased risk of colonic disease. Further studies are required to determine if these potentially unfavourable effects of an LC diet on bowel health are sustained in the long term and whether the inclusion of foods rich in specific types of fermentable carbohydrates such as resistant starches can promote bowel health.

\section{Acknowledgements}

We thank the volunteers who made the study possible through their participation. We gratefully acknowledge: Kathryn Bastiaans, Julia Weaver, Anne McGuffin and Vanessa Courage for coordinating this trial; Xenia Cleanthous, Julianne McKeough and Gemma Williams for assisting in the design of the diets and delivering the dietary intervention; Rosemary McArthur for assisting with the processing of the biological specimen; Debbie Davies, Paul Orchard, Corinna Bennett and Rhys Bushell for assisting with the faecal and urine analysis; Julie Syrette for data management. 
The authors' responsibilities were as follows: G. D. B., conception and design of the study, trial coordination, all statistical analyses, data interpretation and writing of the manuscript; M. N., design of the dietary protocols and contribution to the experimental design, data interpretation and writing of the manuscript; P. M. C., contribution to the experimental design, data interpretation and writing of the manuscript; A. R. B., contribution to the experimental design, data interpretation and writing of the manuscript. All authors agreed on the final version of the manuscript and none had any personal or financial conflict of interest.

The present study was supported by project grants from the National Heart Foundation of Australia and the National Health and Medical Research Council of Australia. We would like to thank Simplot Australia, Mt Buffalo Hazelnuts, Victoria, Webster Walnuts, Victoria, Stahmann Farms, Queensland and Scalzo Food Industries, Victoria for their donation of foods for the present study. None of the funding agencies played a role in the conception, design or conduct of the study, collection, management, analysis and interpretation of the data; or preparation, review and approval of the manuscript.

\section{References}

1. Astrup A, Meinert Larsen T \& Harper A (2004) Atkins and other low-carbohydrate diets: hoax or an effective tool for weight loss? Lancet 364, 897-899.

2. Westman EC, Feinman RD, Mavropoulos JC, et al. (2007) Lowcarbohydrate nutrition and metabolism. Am J Clin Nutr 86, 276-284.

3. US Department of Health Services, Public Health Service (1988) The Surgeon General's Report on Nutrition and Health. Washington, DC: US Government Printing Office.

4. Anderson JW, Smith BM \& Gustafson NJ (1994) Health benefits and practical aspects of high-fiber diets. Am J Clin Nutr 59, 1242S-1247S.

5. Freedman M, King J \& Kennedy E (2001) Popular diets: a scientific review. Obes Res 9, $1 \mathrm{~S}-40 \mathrm{~S}$.

6. Gordon DT (2007) Dietary fibre definitions at risk. Cereal Foods World 52, 112-123.

7. Topping DL \& Clifton PM (2001) Short-chain fatty acids and human colonic function: roles of resistant starch and nonstarch polysaccharides. Physiol Rev 81, 1031-1064.

8. Topping DL \& Bird AR (1999) Food, nutrients and digestive health. Aust J Nutr Dietet 56, S22-S34.

9. Cummings JH (1997) The Large Intestine in Nutrition and Disease. Brussels, Belgium: Institut Danone.

10. Young GP (2000) Colorectal disorders: a dietary management perspective. Asia Pacific J Clin Nutr 9, S76-S82.

11. O'Keefe SJ (2008) Nutrition and colonic health: the critical role of the microbiota. Curr Opin Gastroenterol 24, 51-58.

12. Crowe TC (2005) Safety of low-carbohydrate diets. Obes Rev 6 , 235-245.

13. Kang HC, Chung DE, Kim DW, et al. (2004) Early- and late-onset complications of the ketogenic diet for intractable epilepsy. Epilepsia 45, 1116-1123.

14. Baron JA, Schori A, Crow B, et al. (1986) A randomized controlled trial of low carbohydrate and low fat/high fiber diets for weight loss. Am J Public Health 76, 1293-1296.

15. Yancy WS Jr, Olsen MK, Guyton JR, et al. (2004) A low-carbohydrate, ketogenic diet versus a low-fat diet to treat obesity and hyperlipidemia: a randomized, controlled trial. Ann Intern Med 140, 769-777.
16. Duncan SH, Belenguer A, Holtrop G, et al. (2007) Reduced dietary intake of carbohydrates by obese subjects results in decreased concentrations of butyrate and butyrate-producing bacteria in feces. Appl Environ Microbiol 73, 1073-1078.

17. Halyburton AK, Brinkworth GD, Wilson CJ, et al. (2007) Lowand high-carbohydrate weight-loss diets have similar effects on mood but not cognitive performance. Am J Clin Nutr 86, 580-587.

18. Grundy SM, Cleeman JI, Daniels SR, et al. (2005) Diagnosis and management of the metabolic syndrome. An American Heart Association/National Heart, Lung, and Blood Institute scientific statement. Circulation 112, 2735-2752.

19. Lewis SJ \& Heaton KW (1997) Stool form scale as a useful guide to intestinal transit time. Scand $J$ Gastroenterol 32, 920-924.

20. Hodge A, Patterson AJ, Brown WJ, et al. (2000) The Anti Cancer Council of Victoria FFQ: relative validity of nutrient intakes compared with weighed food records in young to middle-aged women in a study of iron supplementation. Aust N Z J Public Health 24, 576-583.

21. Murray KE \& Adams RF (1988) Determination of simple phenols in faeces and urine by high-performance liquid chromatography. J Chromatogr 431, 143-149.

22. Yoshikawa M, Taguchi Y, Arashidani K, et al. (1986) Determination of cresols in urine by high-performance liquid chromatography. J Chromatogr 362, 425-429.

23. Vreman HJ, Dowling JA, Raubach RA, et al. (1978) Determination of acetate in biological material by vacuum microdistillation and gas chromatography. Anal Chem 50, 1138-1141.

24. Bird AR, Vuaran MS, King RA, et al. (2008) Wholegrain foods made from a novel high-amylose barley variety (Himalaya 292) improve indices of bowel health in human subjects. $\mathrm{Br} \mathrm{J} \mathrm{Nutr}$ 99, $1032-1040$.

25. Chaney AL \& Marbach EP (1962) Modified reagents for determination of urea and ammonia. Clin Chem 8, 130-132.

26. National Health and Medical Research Council (2005) Dietary fibre. In Nutrient Reference Values for Australia and New Zealand, pp. 45-49. Canberra, Australia: National Health and Medical Research Council.

27. Cummings JH, Hill MJ, Jivraj T, et al. (1979) The effect of meat protein and dietary fiber on colonic function and metabolism. I. Changes in bowel habit, bile acid excretion, and calcium absorption. Am J Clin Nutr 32, 2086-2093.

28. Cummings JH, Wiggins HS, Jenkins DJ, et al. (1978) Influence of diets high and low in animal fat on bowel habit, gastrointestinal transit time, fecal microflora, bile acid, and fat excretion. J Clin Invest 61, 953-963.

29. Burkitt DP, Walker AR \& Painter NS (1972) Effect of dietary fibre on stools and the transit-times, and its role in the causation of disease. Lancet ii 1408-1412.

30. Spiller GA (1978) Interaction of dietary fiber with other dietary components: a possible factor in certain cancer etiologies. Am J Clin Nutr Suppl. 10, 31, S231-S232.

31. Birkett AM, Jones GP, de Silva AM, et al. (1997) Dietary intake and faecal excretion of carbohydrate by Australians: importance of achieving stool weights greater than $150 \mathrm{~g}$ to improve faecal markers relevant to colon cancer risk. Eur J Clin Nutr 51, $625-632$

32. Cummings JH, Bingham SA, Heaton KW, et al. (1992) Fecal weight, colon cancer risk, and dietary intake of nonstarch polysaccharides (dietary fiber). Gastroenterology 103, 1783-1789.

33. Lewis SJ \& Heaton KW (1997) Increasing butyrate concentration in the distal colon by accelerating intestinal transit. Gut 41, 245-251.

34. Kiefer J, Beyer-Sehlmeyer G \& Pool-Zobel BL (2006) Mixtures of SCFA, composed according to physiologically available concentrations in the gut lumen, modulate histone acetylation in human HT29 colon cancer cells. Br J Nutr 96, 803-810. 
35. Bingham SA (1999) High-meat diets and cancer risk. Proc Nutr Soc 58, 243-248.

36. Cummings JH \& Bingham SA (1987) Dietary fibre, fermentation and large bowel cancer. Cancer Surv 6, 601-621.

37. Muir JG, Yeow EG, Keogh J, et al. (2004) Combining wheat bran with resistant starch has more beneficial effects on fecal indexes than does wheat bran alone. Am J Clin Nutr $\mathbf{7 9}$, $1020-1028$.

38. Silvester KR \& Cummings JH (1995) Does digestibility of meat protein help explain large bowel cancer risk? Nutr Cancer $\mathbf{2 4}$, 279-288.

39. Toden S, Bird AR, Topping DL, et al. (2005) Resistant starch attenuates colonic DNA damage induced by higher dietary protein in rats. Nutr Cancer 51, 45-51.

40. Birkett A, Muir J, Phillips J, et al. (1996) Resistant starch lowers fecal concentrations of ammonia and phenols in humans. Am J Clin Nutr 63, 766-772.

41. Toden S, Bird AR, Topping DL, et al. (2007) Differential effects of dietary whey, casein and soya on colonic DNA damage and large bowel SCFA in rats fed diets low and high in resistant starch. Br J Nutr 97, 535-543.

42. Toden S, Bird AR, Topping DL, et al. (2007) High red meat diets induce greater numbers of colonic DNA double-strand breaks than white meat in rats: attenuation by high-amylose maize starch. Carcinogenesis 28, 2355-2362.

43. Bingham SA (2000) Diet and colorectal cancer prevention. Biochem Soc Trans 28, 12-16.

44. Le Leu RK, Brown IL, Hu Y, et al. (2005) A synbiotic combination of resistant starch and Bifidobacterium lactis facilitates apoptotic deletion of carcinogen-damaged cells in rat colon. J Nutr 135, 996-1001.

45. Gibson GR, Probert HM, van Loo JAE, et al. (2004) Dietary modulation of the human colonic microbiota: updating the concept of prebiotics. Nutr Res Rev 17, 259-275.

46. Meijer-Severs GJ \& van Santen E (1987) Short-chain fatty acids and succinate in feces of healthy human volunteers and their correlation with anaerobe cultural counts. Scand J Gastroenterol 22, 672-676.

47. Heavey PM \& Rowland IR (2004) Microbial-gut interactions in health and disease. Gastrointestinal cancer. Best Pract Res Clin Gastroenterol 18, 323-336.

48. Guarner F \& Malagelada JR (2003) Gut flora in health and disease. Lancet 361, 512-519.

49. Hill MJ, Drasar BS, Hawksworth G, et al. (1971) Bacteria and aetiology of cancer of large bowel. Lancet i 95-100.

50. Mai V \& Morris JG Jr (2004) Colonic bacterial flora: changing understandings in the molecular age. $J$ Nutr 134, 459-464. 